\title{
Microwave Assisted Hydrolysis of Cellulose to Release Sugars from Pongamia Oil Cake for its use in Bioethanol Production
}

\author{
H. VENKATESH KAMATH, ASHWINI G. SHENOY, INCHARA CRASTA, \\ SOUMYA M. RAO, K. B. UDBHAVI and C. VAMAN RAO*
}

Department of Biotechnology Engineering, N.M.A.M. Institute of Technology, Nitte-574 110, Udupi District, Karnataka, India

vamanrao@nitte.edu.in

Received 19 July 2018 / Accepted 5 August 2018

\begin{abstract}
Biomass based biofuels has been a promising alternative source of energy for the past few decades. The major hurdle is the technologies of production and challenges involved in processing time. This work describes the use microwave radiation to produce bioethanol from a byproduct of biodiesel industry viz., Pongamia pinnata oil seed cake. The powdered oil cake was acid treated under microwave radiation for release of reducing sugars. The kinetics of the microwave process was studied and found that microwave mediated process accelerates the acid hydrolysis of oil cake in comparison with conventional heating method. Further, the multistage process for microwave mediated acid hydrolysis was adapted to increase the overall yield. The yield did not improve beyond 3 stages. The hydrolysate obtained was fermented to produce bioethanol using Saccharomyces cerevisiae.
\end{abstract}

Keywords: Microwave radiation, Acid hydrolysis, Cellulosic Biomass, Biofuels, Bioethanol

\section{Introduction}

The trends in depleting fossil fuels for energy, their increasing cost and global instabilities have driven the interest to search for alternative energy sources. Biofuels, one among such renewable fuels produced from bio-based feedstock. The Indian 'National Policy on Biofuels - 2018' now allows use of several non-edible and waste materials as feedstock for production of biofuels ${ }^{1}$. In the last two decades, several such feedstocks have been used for production of bioethanol, which is one of the biofuel. The composition of raw material determines the sequence of processes involved in bioethanol production. A schematic illustration of the ethanol production from biomass is shown in Figure 1.

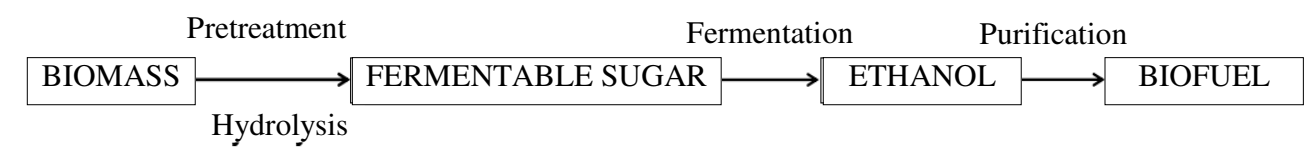

Figure 1. Scheme of biomass based bioethanol production 
A pretreatment step that hydrolyzes complex sugar polymer in the biomass is essential before fermentation to produce ethanol. Several pretreatment methods such as physical treatment, chemical treatment, biological treatment, physicochemical treatment and combination processes have been reported ${ }^{2-4}$. Use of acids or enzymes alters the strength of cellulosic fibers and hydrolyze the polymer to its monomers ${ }^{2}$. Pongamia pinnata is one of the widely used non-edible sources to produce biodiesel in India ${ }^{5,6}$. Doshi and Srivastava ${ }^{7}$ reported reducing sugar yield of $66 \mathrm{mg} / \mathrm{g}$ of seed cake with a conventional pretreatment method by using sulfuric acid. Radhakumari et al., ${ }^{8}$ reported a single step process using $7.5 \%$ sulfuric acid to digest the biomass using an autoclave. In $1 \mathrm{~h}$ of processing they obtained glucose yield of $0.245 \mathrm{~g} / \mathrm{g}$ of seed cake. Apart from sulfuric acid, other acids like hydrochloric acid, acetic acid has been used for the digestion of biomass ${ }^{9}$. Pongamia pinnata oil cake has a great potential for use as feedstock for bioethanol production. But the lesser attempts have been made to improve the processing time. Improvement in processing time enhances the productivity, hence the economics of the process.

Microwave radiation accelerates chemical processes through the intrinsic heat generation because of extensive molecular collisions, vibration of polar molecules and ionic movement ${ }^{10}$. The dielectric properties of the reaction components determine the performance of a microwave process. Microwave has been successfully used for biomass pretreatment process $^{11-13}$. Microwave irradiation accelerates the reaction due to the thermal and non-thermal effects $^{10,14}$. Microwave irradiation also decreases the activation energy of the reaction. In their work on bio-diesel production, Iyyaswami et al.,${ }^{14}$ have confirmed that microwave irradiation interacts with reacting molecules and brings down the activation energy required for reaction.

In this study, microwave radiation is used for hydrolysis of Pongamia pinnata oil cake. Kinetic studies of microwave assisted acid hydrolysis process were performed and compared with conventional heating method. The overall yield of microwave batch process was increased by subjecting the oil cake to multi stage acid hydrolysis process. After, the separation and treatment of hydrolysate, it was used for ethanolic fermentation using Saccharomyces cerevisiae.

\section{Experimental}

The de-oiled cake of Pongamia pinnata was used as biomass for acid hydrolysis experiments. It was procured from a biodiesel production unit which produced biodiesel from Pongamia oil. The composition of the powdered biomass was determined using NREL methods ${ }^{15}$. Soxhlet extraction with chloroform methanol solvent system was used to estimate the lipid composition in the biomass. All the chemicals used were of reagent grade and used without any further modifications.

\section{Microwave assisted acid digestion process}

A microwave oven (Onida, Power Solo 17D) with five fixed power levels was used for all the microwave mediated acid hydrolysis experiments. Since sulfuric acid is one of the most preferred inorganic catalyst for hydrolysis of carbohydrates, it was used as catalyst for all hydrolysis reactions of carbohydrates ${ }^{16}$. In a typical microwave experiment, $6 \mathrm{~g}$ of powdered oil cake was added to sulfuric acid solution in an Erlenmeyer flask and diluted with distilled water to make up the concentration of solids to $6 \%(\mathrm{w} / \mathrm{v})$ and acid concentration to $2 \%(\mathrm{v} / \mathrm{v})$. The sample was exposed to microwave radiation at $140 \mathrm{~W}$ for $5 \mathrm{~min}$ and then it was cooled and centrifuged. The supernatant solution was neutralized with a few drops of concentrated sodium hydroxide solution. Further, it was filtered using Whatman No.1 filter and then the 
filtrate was analyzed for total sugar and reducing sugar concentration. Spectrophotometer based anthrone method for total sugars ${ }^{17}$ and DNS method for reducing sugars ${ }^{18}$ was used for estimation. Glucose was used as standard for both methods.

\section{Kinetics of acid hydrolysis reaction under microwave radiation}

The kinetics of acid hydrolysis reaction to produce reducing sugars from carbohydrates present in oil cake was studied by varying microwave exposure time from $1 \mathrm{~min}$ to $9 \mathrm{~min}$. The kinetic analysis was performed for microwave output powers $140 \mathrm{~W}, 280 \mathrm{~W}$ and $420 \mathrm{~W}$. The acid concentration in the reaction mixture was varied from $1 \%(\mathrm{v} / \mathrm{v})$ to $3 \%(\mathrm{v} / \mathrm{v})$. The product, reducing sugar concentration ${ }^{18}$ was estimated for reaction kinetics analysis.

\section{Multistage microwave mediated hydrolysis of oil cake}

The experimental combination giving higher reducing sugar concentration was used for multistage experiments. The kinetic analysis showed that solids at $6 \%(\mathrm{w} / \mathrm{v})$ with sulfuric acid concentration of $3 \%(\mathrm{v} / \mathrm{v})$ for a reaction time of $6 \mathrm{~min}$ gave higher reducing sugar concentration. Experiments conducted in triplicate followed the same combination for multistage experiment. The experiment scheme is shown in Figure 2. Total sugar and reducing sugar concentration was analyzed at each stage. The yield of sugars at each stage was calculated using Eq. 1 and overall yield using Eq. 2.

$$
\text { Overall sugar yield }=\frac{\sum(\text { Sugar concentrat ion }(\mathrm{g} / \mathrm{L}) \times \text { volume of hydrolysate })(\mathrm{L})}{\text { Solids mass fed in stage } 1(\mathrm{~g})}
$$

Figure 2. Scheme of multistage acid hydrolysis of oil cake

\section{Fermentation of hydrolysates to ethanol}

The acid hydrolysate obtained by microwave mediated process was used for ethanolic fermentation by using Saccharomyces cerevisiae MTCC 171. The reducing sugars concentration was readjusted to $6 \mathrm{~g} / \mathrm{L}$ final hydrolysate broth concentration and autoclaved. No additional nutrients were added. A sub culture of $S$. cerevisiae was grown in nutrient medium for $24 \mathrm{~h}$ and $1 \mathrm{~mL}$ of this was transferred to the autoclaved hydrolysate broth. The culture flasks with hydrolysate and microbe were agitated and incubated at room temperature $\left(25-30{ }^{\circ} \mathrm{C}\right)$ and $150 \mathrm{rpm}$ for 24,48 and 72 hours. The sample was distilled and ethanol was estimated using potassium dichromate method ${ }^{19}$.

\section{Results and Discussion}

\section{Biomass composition}

The composition of Pongamia pinnata oil cake was determined using NREL procedures. Table 1 represents the composition of powdered biomass. The oil cake has about $60 \%$ of the sugar that can be hydrolysed and used for ethanolic fermentation. The lipid present in the biomass depends upon the extent to which oil has been expelled during oil extraction process. 
Table 1. Composition of pressed oil cake of Pongamia pinnata

\begin{tabular}{cc}
\hline Components & $\% \mathrm{w} / \mathrm{w}$ \\
\hline Cellulose & $27.60 \pm 1.17$ \\
Hemicellulose & $31.20 \pm 0.85$ \\
Starch & $1.10 \pm 0.10$ \\
Lignin & $4.20 \pm 0.51$ \\
Protein & $13.10 \pm 1.15$ \\
Lipid & $16.45 \pm 1.13$ \\
Moisture & $3.16 \pm 0.96$ \\
Ash & $5.32 \pm 0.92$ \\
\hline
\end{tabular}

Kinetics of single stage acid hydrolysis facilitated by microwave

Kinetic studies of microwave facilitated acid hydrolysis of oil cake to sugars was conducted at 3 different microwave powers. The sulfuric acid concentration was also varied at these power levels. In Figure 3a. reducing sugar concentration increased with time up to $6 \mathrm{~min}$ at microwave power of $140 \mathrm{~W}$. The concentration remained same beyond $6 \mathrm{~min}$. At $280 \mathrm{~W}$ power, the reducing sugar concentration increased up to $5 \mathrm{~min}$ (Figure $3 \mathrm{~b}$.) and similar trend was observed with microwave power of $420 \mathrm{~W}$ (Figure 3c.). Highest reducing sugar concentration of $7.80 \pm 0.14 \mathrm{~g} / \mathrm{L}$ and total sugar concentration $10.35 \pm 0.58 \mathrm{~g} / \mathrm{L}$ of was obtained at $280 \mathrm{~W}$ and $3 \%(\mathrm{v} / \mathrm{v})$ acid concentration.
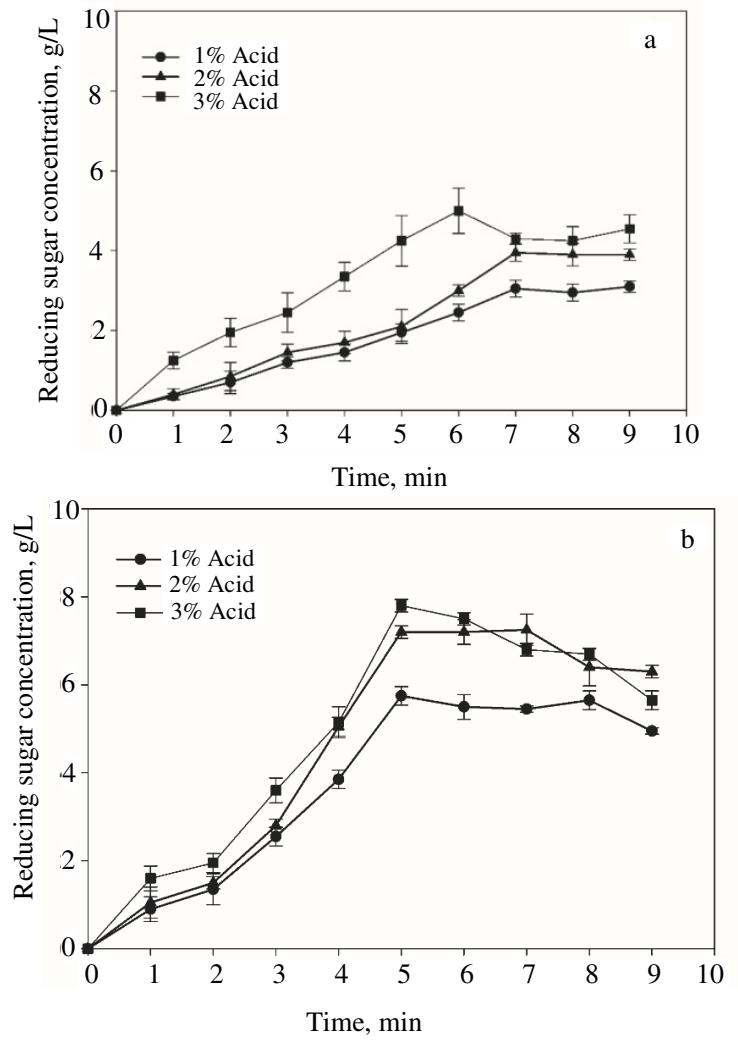


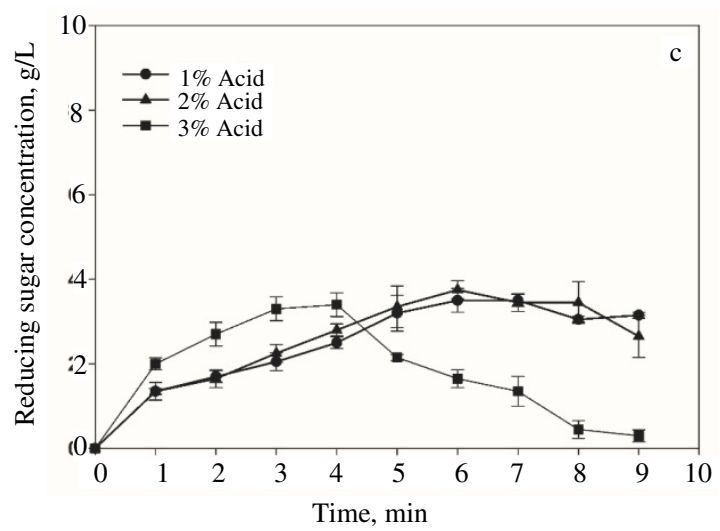

Figure 3. Kinetics of microwave facilitated acid hydrolysis of oil cake at different microwave powers: a) $140 \mathrm{~W}$; b) $280 \mathrm{~W}$; c) $420 \mathrm{~W}$

The sugar concentration was low at $140 \mathrm{~W}$ and $420 \mathrm{~W}$ in comparison with $280 \mathrm{~W}$. There could be two reasons that attribute to this behavior viz., thermal effects and degradation reactions. The thermal effect is due to the microwave heating whereas degradation reaction is due to the further conversion of sugars to furfurals $\mathrm{s}^{20}$. At $140 \mathrm{~W}$, the temperature of reaction mixture $\left(40-60^{\circ} \mathrm{C}\right)$ was much lower in comparison with temperature at $420 \mathrm{~W}\left(80-100{ }^{\circ} \mathrm{C}\right)$. The thermal effect caused the variation in rate of reaction by altering the rate constants of the reaction ${ }^{13,14}$. Thus, it was expected that as the microwave power increased from $140 \mathrm{~W}$ to $420 \mathrm{~W}$, reducing sugar concentration would also increase with time. In contrast, the sugar concentration decreased beyond $5 \mathrm{~min}$ as well as for power above $280 \mathrm{~W}$. This decrease in sugar concentration could be because of further conversion of reducing sugar to its degradation product furfurals. In addition to this effect, reaction mixture was evaporated quickly at $6 \mathrm{~min}$ and beyond when power of $240 \mathrm{~W}$ and $420 \mathrm{~W}$ was administered, which lead to the reduction in sugar concentration. Thus, microwave power of $280 \mathrm{~W}$ with acid concentration $3 \%(\mathrm{v} / \mathrm{v})$ and irradiation time of 5 to 6 min could be a suitable experimental combination to yield high sugar concentration.

\section{Multistage microwave mediated hydrolysis of oil cake}

Based on the kinetic analysis, biomass solids at $6 \%(\mathrm{w} / \mathrm{v})$ was treated with $3 \%(\mathrm{v} / \mathrm{v})$ sulfuric acid for a reaction time of $6 \mathrm{~min}$ at $280 \mathrm{~W}$. The hydrolysate was analyzed for yield of reducing sugar concentration and total sugar concentration. The biomass solids remained after $1^{\text {st }}$ stage was treated again with $3 \%(\mathrm{v} / \mathrm{v})$ acid at $280 \mathrm{~W}$ for $6 \mathrm{~min}$. This procedure was repeated for total 3 stages. The sugar concentration and yield obtained in each stage is shown in Table 2. Maximum amount of sugar was released in first stage. In stages 2 and 3 the sugar concentration is decreased possibly due to the increase in solids to acid ratio. This in turn increased the rate of undesired sugar conversion thereby increasing the concentration of furfurals.

The overall yield is a measure of removal of sugar from the biomass based on initial quantity of biomass supplied to stage 1 . Since the stages were sequential, an analysis of yield progression was done. Of the sugar released in three stages, $1^{\text {st }}$ stage accounted for about $60-70 \%$ of the overall yield. Use of $2^{\text {nd }}$ and/or $3^{\text {rd }}$ stage could improve the sugar yield but at the cost of lower sugar concentrations. To cater to the needs of ethanolic fermentation with broth sugar concentrations greater than $5 \mathrm{~g} / \mathrm{L}$, only single stage hydrolysis is recommended. 
The yield of reducing sugar released is comparatively similar to that produced using conventional methods reported in literature ${ }^{6,7,9}$. Due to the increased rate of reaction, reaction time is reduced by many folds.

Table 2. Sugar concentration and yield in multi stage acid hydrolysis of oil cake

\begin{tabular}{ccccc}
\hline \multirow{2}{*}{ Stage } & \multicolumn{2}{c}{ Concentration, $\mathrm{g} / \mathrm{L}$} & \multicolumn{2}{c}{ Yield, g/kg oil cake } \\
\cline { 2 - 5 } & Reducing sugar & Total sugar & Reducing sugar & Total sugar \\
\hline 1 & $7.71 \pm 0.34$ & $10.02 \pm 0.52$ & $128.4 \pm 5.6$ & $167.0 \pm 8.7$ \\
2 & $3.29 \pm 0.55$ & $5.69 \pm 0.64$ & $51.2 \pm 9.2$ & $117.8 \pm 12.6$ \\
3 & $0.51 \pm 0.18$ & $1.42 \pm 0.35$ & $9.3 \pm 3.3$ & $34.7 \pm 9.4$ \\
Overall & $3.84 \pm 0.08$ & $5.71 \pm 0.21$ & $191.8 \pm 4.1$ & $285.5 \pm 10.3$ \\
\hline
\end{tabular}

Fermentation of single stage oil cake hydrolysate to ethanol

The acid hydrolysate produced from oil cake through single stage process was used to prepare fermentation broth to a final sugar concentration of $6 \mathrm{~g} / \mathrm{L}$. Ethanol yield obtained from Saccharomyces cerevisiae at different incubation time are shown in Figure 4. Ethanol titer of $2.04 \pm 0.23 \mathrm{~g} / \mathrm{L}$ was produced in 72 hours using acid hydrolysate. Though, this ethanol titer is less in comparison with literature reported processes, this process can be improved by utilizing suitable high yielding strains or improving medium composition. This work demonstrates the use of acid hydrolysate obtained from microwave mediated process to produce ethanol.

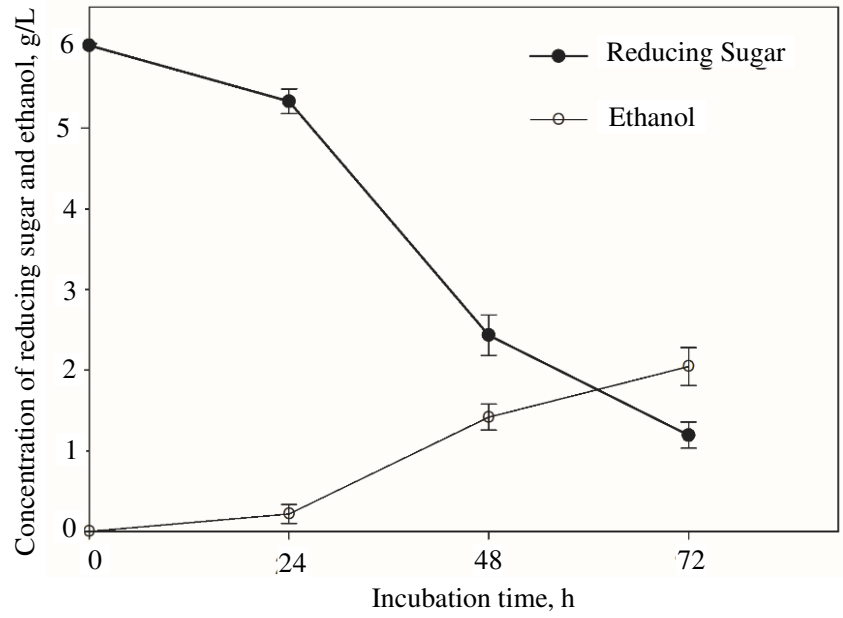

Figure 4. Ethanol production from acid hydrolysate of oil cake after incubating with Saccharomyces cerevisiae at different time intervals

\section{Conclusion}

Use of microwave radiation was demonstrated as a suitable heating medium for acid hydrolysis of Pongamia pinnata oil cake. This process released reducing sugar and use of multi stage process did not improve the sugar concentration. Hence it is suggested to use single stage process. The hydrolysate was fermented to produce ethanol using yeast. Although the ethanol produced was less, process can be improved using further using suitable improvisation techniques. This work demonstrated the use of byproduct of biodiesel industry as a suitable feedstock for bioethanol production. 


\section{Acknowledgment}

This research was funded by Vision Group on Science and Technology (VGST) Bengaluru, Government of Karnataka, India under the VGST-CISEE scheme grant number [GRD198]. The authors would like to thank Udupi district Bioenergy Research and Demonstration Centre, Nitte for providing the necessary oil cake for the experimental work and related information.

\section{Conflict of interest}

The authors declare no competing financial interest.

\section{References}

1. National Policy on Biofuels - 2018, Ministry of Petroleum \& Natural Gas, Govt. of India., http://petroleum.nic.in/national-policy-biofuel-2018-0, (accessed 30 June 2018).

2. Amin F R, Khalid H, Zhang H, Rahman S u, Zhang R, Liu G and Chen C, $A M B$ Express; 2017, 7, 72; DOI:10.1186/s13568-017-0375-4

3. Chaturvedi V and Verma P, Biotech., 2013, 3(5), 415-431; DOI:10.1007/s13205-0130167-8

4. Jönsson L J and Martín C, Bioresour Technol., 2016, 199, 103-112; DOI: 10.1016/j.biortech.2015.10.009.

5. Dalemans F, Muys B, Verwimp A, Van den Broeck G, Bohra B, Sharma N, Gowda B, Tollens E and Maertens M, Energ Policy, 2018, 115, 631-643; DOI:10.1016/j.enpol.2018.01.030

6. Radhakumari M, Taha M, Shahsavari E, Bhargava S K, Satyavathi B and Ball A S, Renew Energ., 2017, 103, 682-687; DOI:10.1016/j.renene.2016.10.082

7. Doshi P and Srivastava G, Turk J Agric Forestry, 2013, 37, 781-788; DOI:10.3906/tar-1207-18

8. Radhakumari M, Ball A, Bhargava S K and Satyavathi B, Bioresour Technol., 2014, 166, 534-540; DOI:10.1016/j.biortech.2014.05.065

9. Muktham R, Ball A S, Bhargava S K and Bankupalli S, Ind Crop Prod., 2016, 94, 490-497; DOI:10.1016/j.indcrop.2016.09.019

10. Sridar V, Curr Sci., 1998, 74(5), 446-450;

11. Marx S, Ndaba B, Chiyanzu I and Schabort C, Biomass Bioenerg., 2014, 65, 145-150; DOI:10.1016/j.biombioe.2013.11.019

12. Saha B C, Biswas A and Cotta M A, J Biobased Materials Bioenerg., 2008, 2(3), 210-217; DOI:10.1166/jbmb.2008.412

13. Saifuddin N and Hussain R, Chem Sci Trans., 2014, 3(1), 350-358; DOI: $10.7598 /$ cst2014.669

14. Iyyaswami R, Halladi V K, Yarramreddy S R and Malur Bharathaiyengar S, Biomass Conver Bioref., 2013, 3(4), 305-317; DOI:10.1007/s13399-013-0080-8

15. Sluiter J B, Ruiz R O, Scarlata C J, Sluiter A D and Templeton D W, J Agric Food Chem., 2010, 58(16), 9043-9053; DOI:10.1021/jf1008023

16. Wilkinson S, Greetham D, and Tucker G A, Biofuel Res J., 2016, 3, 357-365; DOI:10.18331/BRJ2016.3.1.5

17. Scott T A and Melvin E H, Analyt Chem., 1953, 25(11), 1656-1661; DOI:10.1021/ac60083a023

18. Miller G L, Analyt Chem., 1959, 31(3), 426-428; DOI:10.1021/ac60147a030

19. Caputi A, Ueda M, and Brown T, Am J Enol Vitic., 1968, 19, 160-165.

20. Kim D, Molecules, 2018, 23(2), 309; DOI:10.3390/molecules23020309 